\title{
A terapia focada na solução e suas aproximações ao discurso construcionista social
}

\author{
Solution-focused therapy and its relationship \\ to the social constructionist discourse
}

\author{
Pedro Pablo Sampaio MARTINS \\ Carla Pellicer dos SANTOS ${ }^{2}$ \\ Emerson Fernando RASERA ${ }^{3}$
}

\begin{abstract}
Resumo
Buscando contribuir com a reflexão sobre a constituição heterogênea da clínica construcionista social, marcada por diferentes vocabulários e posturas terapêuticos, este artigo analisa as relações entre o discurso construcionista social e os conceitos e práticas da Terapia Focada na Solução, descrita por alguns autores como partilhando ênfases promovidas pelo construcionismo. Por meio de seleção da literatura e da análise conceitual e comparativa, identificam-se pontos de convergência - especialmente a ênfase nas potencialidades e na ação e o abandono da procura por descrições essencialistas sobre a realidade do cliente -, e também de divergência -, a postura terapêutica diretiva e de especialidade, o foco em mudanças comportamentais e a concepção individualista de self presentes na Terapia Focada na Solução. Conclui-se que a Terapia Focada na Solução pode ser uma opção discursiva útil e convida-se a uma reflexão sobre suas implicações para cada contexto terapêutico situado.
\end{abstract}

Unitermos: Construcionismo; Psicoterapia; Terapia focada na solução.

\begin{abstract}
The aim of this study is to contribute to the reflection regarding the heterogeneous constitution of social constructionist psychotherapy, characterized by different vocabularies and postures. This article analyses the relationship between the social constructionist discourse and Solution-focused Therapy concepts and practices, which are described by some authors as sharing the emphasis promoted by social constructionism. Through a selection of the literature and conceptual and comparative analysis, we identified points of similarity-especially the emphasis in potentialities and action and the abandoning of the quest for essential descriptions about the client's reality - and also differences - the directive and specialist therapeutic stance, the focus on behavioral changes and the individualist concept of self sustained by Solution-focused Therapy. We concluded that Solution-focused Therapy can be a useful discursive option and we invite a reflection about its implications in each therapeutic context.
\end{abstract}

Uniterms: Constructionism; Psychotherapy; Solution-focused therapy.

$\boldsymbol{\nabla} \nabla \nabla \nabla$

1 Universidade de São Paulo, Faculdade de Filosofia, Ciências e Letras de Ribeirão Preto. Av. Bandeirantes, 3900, Monte Alegre, 14040-901, Ribeirão Preto, SP, Brasil. Correspondência para/Correspondence to: P.P.S. MARTINS. E-mail: <pedropablomartins@gmail.com>.

2 Pontifícia Universidade Católica de São Paulo, Programa de Pós-Graduação em Psicologia. São Paulo, SP, Brasil.

3 Universidade Federal de Uberlândia, Instituto de Psicologia. Uberlândia, MG, Brasil.

Apoio: Conselho Nacional de Desenvolvimento Científico e Tecnológico.

Agradecimentos: À Renata Y. Okubo pela colaboração em etapa inicial desta pesquisa. 
A clínica construcionista social é marcada por uma variedade de propostas terapêuticas que, apesar de compartilharem alguns pressupostos, caracterizam-se por diferentes vocabulários e posturas terapêuticas (Gergen, 1999; Grandesso, 2000; Guanaes, 2006; McNamee \& Gergen, 1998; Rasera \& Japur, 2004). Buscando contribuir com a reflexão sobre a constituição heterogênea dessa clínica, este artigo analisará as relações entre o discurso construcionista social ${ }^{4}$ e os conceitos e práticas da Terapia Focada na Solução.

Historicamente, a incorporação do construcionismo social na clínica se deu por meio de dois modos privilegiados: a) diferentes grupos de terapeutas familiares que estavam desenvolvendo novas propostas terapêuticas nas décadas de 1980 e 1990 passaram a utilizar as teorizações construcionistas sociais na justificativa e fundamentação de seus trabalhos, tais como a Abordagem Colaborativa (Anderson, 1997) e os Processos Reflexivos (Andersen, 1999); e b) autores reconhecidamente construcionistas (Gergen \& Warhuus, 2001; K.J. Gergen \& M. Gergen, 2010), em tentativas de identificar possíveis aproximações da clínica às leituras construcionistas sobre a construção da realidade, nomearam determinadas abordagens inovadoras, como a Terapia Narrativa de White e Epston (1990) e a Terapia Focada na Solução de Shazer (1994), como partilhando ênfases promovidas pelo construcionismo social.

Enquanto o primeiro modo de aproximação gerou um rápido processo de incorporação e reconhecimento, o segundo deixou em aberto tal possibilidade de identificação e associação. Por um lado, curiosamente, nem White, nem de Shazer chegaram a se autointitular construcionistas sociais. Por outro lado, a comunidade de clínicos construcionistas, especialmente no Brasil, facilmente se interessou pelas contribuições da Terapia Narrativa, colocando-a em diálogo com as outras propostas construcionistas, enriquecendo a clínica cotidiana e as pesquisas na área (Carrijo \& Rasera, 2010; Grandesso, 2000; Rasera \& Japur, 2007), não ocorrendo o mes-mo com a Terapia Focada na Solução.

Nesse sentido, é importante investigar, numa perspectiva teórica e conceitual, como as propostas da
Terapia Focada na Solução se articulam a um discurso construcionista social sobre a psicoterapia, e refletir sobre as possíveis aproximações e distanciamentos. Buscando responder a essa necessidade, o objetivo deste estudo é analisar a constituição e a estrutura da Terapia Focada na Solução, em seus aspectos teórico-metodológicos, bem como compreender as tensões epistemológicas decorrentes do exercício de aproximação da proposta ao discurso construcionista social.

Afirmando o construcionismo como um discurso mutante e múltiplo sobre a prática psicológica (Gergen, 2006; Holzman \& Mendes, 2003; Rasera \& Japur, 2004), não se buscará realizar uma análise que conclua sobre a adequação da inclusão dessa proposta no campo construcionista, mas que aponte os pontos de ruptura, de desvio e estranhamento que convidam a novos questionamentos sobre o próprio discurso construcionista na clínica. Além disso, tal exercício analítico permitirá ampliar o conjunto de ferramentas para a intervenção terapêutica, guiado por uma postura reflexiva que reconhece que diferentes práticas, em diversos contextos situados, podem ser potencialmente transformadoras (Gergen \& Warhuus, 2001).

Para isso, apresentam-se os fundamentos teórico-metodológicos desta abordagem e suas práticas terapêuticas a partir de seus textos fundadores. Em seguida, por meio de uma análise conceitual e comparativa, serão apontadas possíveis aproximações e distanciamentos das descrições da Terapia Focada na Solução do discurso construcionista social para o campo da terapia.

\section{Fundamentos e técnicas da terapia focada na solução}

A Terapia Focada na Solução é uma proposta psicoterápica inserida no contexto da terapia familiar sistêmica, cujo foco está voltado para as possibilidades e competências do cliente. Ela se desenvolveu por meio da colaboração de diversos autores vinculados ao Centro de Terapia Familiar Breve, liderado por Steve de Shazer. Devido à importância desse autor, sua obra será tomada como objeto de reflexão nesta análise dos fundamentos e da estrutura da Terapia Focada na Solução.

\section{2}

$\boldsymbol{\nabla} \boldsymbol{\nabla} \boldsymbol{\nabla}$

4 Neste artigo, utiliza-se a expressão'discurso' construcionista, entendendo que o construcionismo social é um campo de descrições e justificativas sócio-historicamente situado, que produz determinados dizeres e fazeres, sustentando e sendo sustentado por um conjunto diversificado de obras e autores. 
Steve de Shazer iniciou seus estudos com base nas formulações de Milton Erickson (Erickson, E. Rossi \& S. Rossi, 1976), quando se voltou ao estudo e à prática da terapia breve (de Shazer, 1985). Ficou fascinado com o modo como Erickson escrevia sobre sua abordagem, uma vez que ela não parecia ser uma psicoterapia padrão, pois atribuía grande ênfase à especificidade e à unicidade de cada caso clínico. Inspirado por essa ideia, e considerando a variedade e a diversidade como essência da proposta desenvolvida por Erickson, de Shazer (1988) começou a trazer para seu trabalho a compreensão de que o foco terapêutico devesse ser direcionado para as particularidades e idiossincrasias das situações e para as atividades desenvolvidas a partir delas. O interesse não deveria, assim, ser a construção de uma teoria universalizante ou a delimitação e fixação dentro de uma abordagem única diante dos problemas.

À medida que desenvolvia seu pensamento teórico e prático, de Shazer veio a se interessar por leituras sobre filosofia da linguagem e sociologia do conhecimento, em geral, e pela teoria da linguagem proposta por Wittgeinstein (1975), em particular. Tal influência levou-o a uma compreensão da linguagem como um conjunto de possibilidades lógicas para construir uma descrição particular de algo, ou seja, as palavras possuiriam significados construídos histórica e socialmente, passíveis de serem (re)significadas por meio do uso nas diversas relações, em contextos situados. Essa ideia influenciou a construção de um modelo psicoterápico pautado na linguagem (de Shazer, 1991).

Atravessados por essas concepções, os pressupostos da proposta terapêutica focada na solução podem ser elencados como: a) cada pessoa constrói significações próprias acerca de suas experiências individuais, o que influencia na construção da queixa trazida; b) as queixas se mantêm pela crença de que as tentativas de solução, até então utilizadas, são as mais lógicas e coerentes; c) mudanças mínimas são suficientes para gerar soluções desejadas; d) há a possibilidade de desenvolvimento de mudanças adicionais às do contexto terapêutico em relações externas à terapia; e e) uma mudança em um elemento ou em uma relação afeta outros elementos e relacionamentos que, em conjunto, formam um sistema (de Shazer, 1985). Esses pressupostos direcionam a prática clínica, seus conceitos e técnicas, para uma intervenção focada na con- versa entre terapeuta e cliente no contexto terapêutico situado e para a construção de futuros preferíveis.

A Terapia Focada na Solução, como uma forma de terapia breve, preocupa-se em solucionar o quanto antes as queixas, possibilitando ao paciente uma vida com maior satisfação. Terapias breves, em geral, atentam-se apenas para a realização de seis a dez sessões, adequando o modelo terapêutico a esse limite de tempo. Já o foco da Terapia Focada na Solução caracteriza-se pela centralidade das conversas sobre momentos em que o problema não acontece, o que acaba por permitir maior brevidade ao processo terapêutico (de Shazer, 1985; Sharry, 2001).

Além de permitir conhecer a visão de mundo do cliente, tais conversas dão visibilidade ao que corresponderia ao sucesso da terapia. Conversar sobre o que o problema não é possibilita que o terapeuta e o cliente construam juntos a solução, ou ao menos comecem a construí-la, permitindo ao cliente fazer algo diferente das tentativas realizadas e que não obtiveram sucesso. Para isso, os discursos terapêuticos são pautados nas "exceções" - momentos sem a queixa - e nos "milagres" -, momentos imaginados, em que não existiria o problema (DeJong \& Berg, 2008; de Shazer, 1988).

Nesse processo de construção da mudança, os terapeutas focados na solução atentam para a importância de se estabelecerem metas para a terapia; de Shazer (1985) afirma que, sem isso, terapeutas e clientes estarão mais suscetíveis a andar nos mesmos círculos já percorridos em tentativas anteriormente fracassadas. O estabelecimento de metas permite criar a expectativa de um futuro diferente, por meio do qual mudanças no comportamento se tornam possíveis. Isso se dá uma vez que cliente e terapeuta, ao conversarem sobre os objetivos da terapia e o que se espera dela, estão, ao mesmo tempo, abrindo possibilidades para que soluções sejam desenvolvidas. Assim, o conceito de ajuste se torna importante nessa proposta terapêutica, com a compreensão de que não é necessário entender toda a formulação e organização de um problema a fim de se direcionar para uma solução. Pelo contrário, é necessário apenas que a intervenção terapêutica se ajuste àquela construção de problema de maneira que ela seja uma pequena diferença em direção à solução - uma diferença que faça diferença (Bateson, 1972). 
Além das conversas sobre exceções e do estabelecimento de metas, a construção do processo terapêutico focado na solução é marcada por práticas conversacionais características, tais como: a pergunta do milagre, a prescrição de tarefas de casa e as perguntas de escala. Elas estão resumidamente apresentadas no Quadro 1, com exemplos de formulação e as funções a que se prestam.

O uso dessas técnicas explicita as diversas influências teóricas na constituição do modelo terapêutico em questão, na medida em que é possível perceber como o foco na linguagem, característico do pensamento pós-moderno, está associado a uma atitude seletiva e propositiva, típica dos modelos modernos de terapia que contam com um terapeuta ativo e que controla o processo. Dessa forma, as técnicas mostram como no processo de construção da Terapia Focada na
Solução as marcas ericksonianas se fazem muito presentes, não sendo completamente reformuladas a partir da incorporação das contribuições de Wittgenstein, e apontam para uma tensão constitutiva desse modelo terapêutico.

Diante da apresentação sobre a teoria e técnica da Terapia Focada na Solução, e considerando especificamente a variedade de conhecimentos pelos quais ela foi influenciada, passa-se, a seguir, a considerá-la em diálogo com as propostas construcionistas sociais para o campo da terapia.

\section{A terapia focada na solução e o discurso construcionista social}

A compreensão construcionista da terapia como um processo de construção relacional convida à reflexão

\section{Quadro 1}

Técnicas focadas na solução: suas funções e exemplos

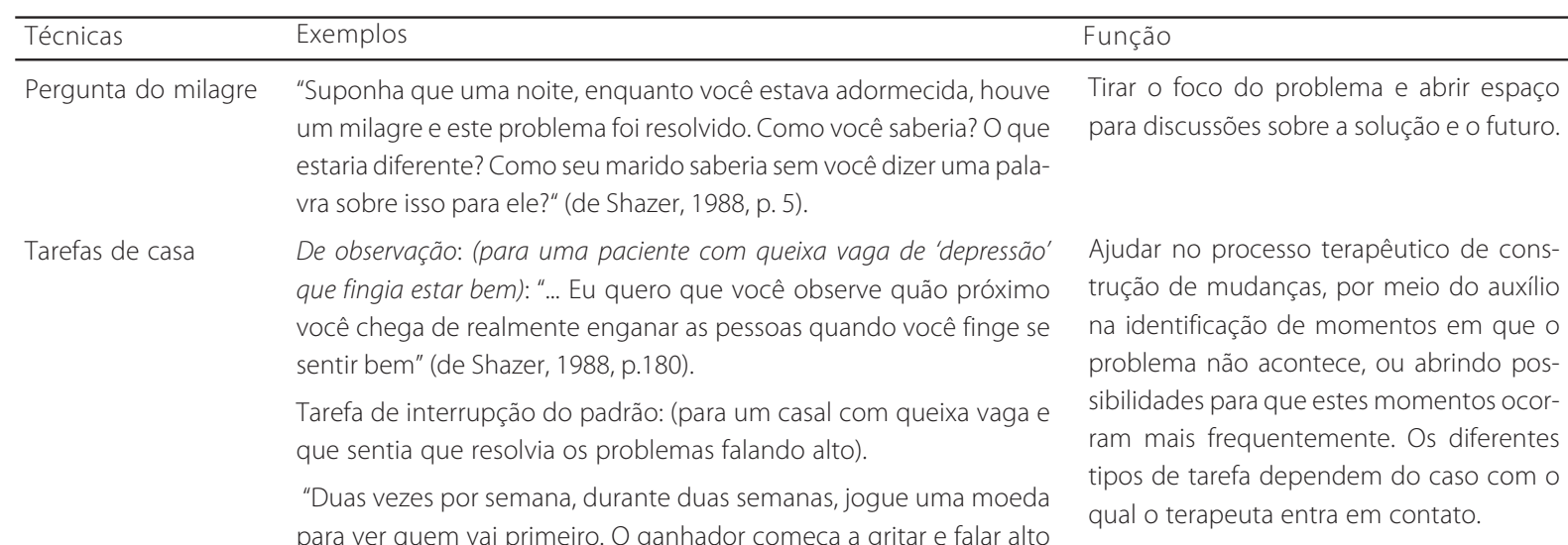
para ver quem vai primeiro. O ganhador começa a gritar e falar alto sobre qualquer coisa ao outro por dez minutos, ininterruptos. 0 perdedor deve apenas fingir ouvir. Então o perdedor tem dez minutos para falar alto e gritar - sobre qualquer coisa ... se a moeda disser 'não' na próxima rodada ou após dez minutos de silêncio, pela segunda vez, os dois vão fazer alguma atividade física juntos" (de Shazer, 1988, p.165).

A fim de continuar a agir de acordo com as exceções:

"... uma vez que você encontrou o que funciona para você, apenas posso sugerir que você continue fazendo o que você fez na semana passada" (de Shazer, 1988, p.147).

De estabelecer previsões:

"... cada noite antes de ir para a cama, quero que você decida quais das oito coisas da lista serão mais simples de fazer, para você, no dia seguinte" (de Shazer, 1988, p. 129).

Perguntas de escala "Da última vez, você estava falando sobre ter ficado deprimido por um longo tempo. Vamos supor que 10 signifique 'de volta ao normal' e 'sem depressão' e 0 seja tão mal, tão deprimido quanto você já se 114 sentiu, onde você se colocaria hoje?" (de Shazer, 1991, p.148).

Permitir que, por meio de números, o cliente descreva sua percepção sobre a situação e ainda, encorajar a elucidação de metas e soluções. 
sobre o próprio processo de mudança e sobre as opções terapêuticas disponíveis. Éassim que, em vez de priorizar técnicas específicas, o objetivo do debate pós-moderno sobre terapia é estimular a ampliação das possibilidades terapêuticas sensíveis aos pressupostos que caracterizam esse campo.

Segundo Gergen e Warhuus (2001), a presença do construcionismo social na clínica influencia mudanças tanto na postura quanto nas práticas terapêuticas. Assim, o convite construcionista favorece posturas que se direcionam à flexibilidade, à consciência da construção social, à colaboração e ao reconhecimento dos valores envolvidos no fazer terapêutico. Quanto às práticas, elas tendem a se direcionar para o discurso, as relações, a polivocalidade, as potencialidades e as ações. Considerando cada um desses movimentos, serão tratadas as possibilidades de aproximação das posturas e das práticas terapêuticas da Terapia Focada na Solução àquelas associadas a um discurso construcionista social.

\section{A terapia focada na solução e as posturas construcionistas}

No que tange às implicações para a postura terapêutica, o primeiro movimento identificado pela análise de Gergen e Warhuus (2001) trata de uma mudança da busca de fundamentos que guiam o fazer terapêutico, característica marcante de uma concepção moderna empirista de produção do conhecimento, para uma postura de flexibilidade. Para o construcionismo social, teorias guiam as interpretações do mundo empírico e, portanto, não podem ser consideradas como tendo um status de verdade transcendente para além de um contexto específico de produção. Dessa forma, em vez de se buscar uma única visão que dê conta do funcionamento humano, o convite pós-moderno está em uma flexibilidade que permita ao terapeuta percorrer as diversas possibilidades úteis ao processo terapêutico.

A esse respeito, pode-se dizer que a Terapia Focada na Solução se aproxima da postura construcionista na medida em que de Shazer (1988) destaca a influência pós-estruturalista no contexto de desenvolvimento desse modelo psicoterápico. É assim que sua característica mais marcante apresenta um traço claramente pós-moderno: não énecessário que se compreenda a maneira de funcionamento de um problema, sua origem e fundamento, a fim de solucioná-lo. Tal ponto de partida, utilizado por terapeutas focados na solução, torna-se possível conforme eles compreendem que há possibilidade de busca por alternativas que não partilham da necessidade moderna de diagnóstico, pautada pela decodificação, sistematização e compreensão de um problema para sua solução. As intervenções, assim, precisam apenas se ajustar à queixa do cliente, especificamente, sem a necessidade da produção de descrições que correspondam e se adequem a um modelo e a uma realidade externa, independente e já dada.

Ainda nesse sentido, a Terapia Focada na Solução se aproxima da postura construcionista de flexibilidade na medida em que a busca por soluções, ao mesmo tempo em que mantém uma criteriosa forma de conduzir a conversa terapêutica e prescrever tarefas, também se permite recorrer a significados culturais alternativos para além daqueles produzidos pela teoria, ou seja, procura intervir a partir do enquadre do próprio cliente, recorrendo também às suas formas de descrição. É importante ressalvar que a Terapia Focada na Solução apresenta um fazer terapêutico sensível à postura de flexibilidade, mas que, ao se postular como uma forma de terapia específica, privilegia determinadas técnicas e intervenções que the são características.

A segunda mudança na postura terapêutica associada ao construcionismo social trata de uma passagem do essencialismo para a consciência da construção. Essa mudança busca chamar a atenção para a terapia como um espaço ativo de negociação de sentidos e construção de realidades, em vez de um lugar que busque por uma descrição única, verdadeira e mais correta por si mesma, capaz de representar a realidade essencial do cliente. Trata-se de uma noção mais amplamente compartilhada pela Terapia Focada na Solução, conforme passou a ser influenciada pelos estudos da filosofia da linguagem, por meio dos quais a compreensão da linguagem como construtora de realidades foi incorporada ao pensamento focado na solução (Berg \& de Shazer, 1993). Esta ênfase construcionista pode ser ilustrada com a "conversa de solução" proposta por essa forma de terapia. Nas palavras dos autores:

"Enquanto cliente e terapeuta conversam mais e mais sobre a solução que querem construir juntos, eles vêm a acreditar na verdade ou realidade sobre o que estão falando. Essa é a maneira que a linguagem funciona, naturalmente" (Berg \& de Shazer, 1993, p.9). 
Como se percebe, a ideia é que terapeutas e clientes escolham sobre o que conversarão durante a terapia, permitindo a construção de diferentes mundos e realidades para os clientes. Tal noção está também intimamente ligada à ênfase no discurso colocada pelo construcionismo para a prática terapêutica. Essa prática é a responsável pelo que Bidwell (2007), em análise teórica sobre as origens epistemológicas da Terapia Focada na Solução, chamou de "virada construcionista".

O terceiro movimento trata da passagem de uma postura de especialidade do terapeuta para outra de colaboração. Trata-se de uma diferença marcante entre a postura terapêutica construcionista social e aquelas advindas de teorias psicológicas modernas, no sentido em que favorece a procura por relações terapêuticas horizontais e colaborativas, nas quais a tradicional posição de autoridade do terapeuta dá lugar à abertura para os diferentes saberes presentes na sessão e para a produção de novos sentidos. Nos termos de Anderson e Goolishian (1998), a terapia seria um encontro de dois especialistas: ao cliente caberia a especialidade do conteúdo - sobre o que se conversa -, enquanto ao terapeuta estaria reservada a especialidade do processo - como a conversa é conduzida.

Pensando nesse movimento em relação à Terapia Focada na Solução, é possível entender que, ao mesmo tempo em que ele parece estar contemplado na teoria e na técnica da citada terapia, considerando, sobretudo, a busca pelo ajuste e por conversas que sejam parte do enquadre do cliente, algumas divergências também se tornam aparentes. Assim, no fazer da Terapia Focada na Solução, o terapeuta assume uma postura extremamente ativa na conversa. Sua especialidade no processo é visível na medida em que há uma clara preocupação com as maneiras pelas quais a conversa pode/deve ser guiada para a construção de soluções. No mesmo processo, entretanto, há também uma determinação por parte do terapeuta do conteúdo a ser conversado: ele intervém com a finalidade de restringir conversas sobre a queixa e direcioná-las para a conversa de solução. As próprias técnicas utilizadas são uma forma clara de interferir no conteúdo da terapia, desde a pergunta do milagre, que têm o objetivo de construir metas e versões de futuros preferidos, até a prescrição de tarefas, que sugere uma intervenção instrutiva e hierárquica.

Isso não quer dizer que o terapeuta focado na 116 solução não se preocupe em criar colaboração na relação terapêutica. Há todo um cuidado para encontrar a maneira pela qual o cliente poderá colaborar com o terapeuta (de Shazer, 1985), mas tal conceito é utilizado com fortes raízes sistêmicas e sugere que o caminho construído siga o fluxo da busca pela colaboração por parte do cliente para com o terapeuta. Essas diferenças não afastam por si mesmas a Terapia Focada na Solução do construcionismo social, uma vez que, para este, nada deve ser necessariamente descartado. A sugestão construcionista seria pensar como, em quais contextos e por quais razões intervenções mais diretivas como essas podem ser úteis na conversa terapêutica e quando podem prejudicá-la.

A última mudança na postura terapêutica à qual o construcionismo social convida se dá em direção ao reconhecimento da relevância dos valores presentes no trabalho terapêutico. Afastando-se da concepção moderna que afirmava a possibilidade e a necessidade de uma terapia neutra e destituída de valores, o construcionismo trabalha com a noção oposta, reconhecendo que toda ação está comprometida com determinados valores éticos, políticos e ideológicos, mesmo que não sejam conhecidos. Isso não seria diferente para a terapia, o que sensibiliza os terapeutas a, por um lado, conhecer e refletir sobre as consequências pragmáticas dos valores com os quais suas ações estão comprometidas, e, por outro, retirar a autoridade final de um conjunto de valores como intrinsecamente superior a qualquer outro, incluindo os do próprio terapeuta.

Os textos fundadores sobre a Terapia Focada na Solução não apresentam, explicitamente, um interesse em refletir sobre seus compromissos éticos, políticos e ideológicos, o que pode ser considerado como um distanciamento da ênfase construcionista. Há, contudo, o compromisso ético com a criação de uma forma de terapia que produza bem-estar para os clientes e seja o mais breve e eficaz possível (de Shazer, 1985).

Tendo analisado os textos sobre Terapia Focada na Solução com relação às quatro tendências para a postura terapêutica construcionista propostas por Gergen e Warhuus (2001), pode-se prosseguir analisando-os segundo os movimentos em direção ao discurso, à relação, à polivocalidade, às potencialidades e à ação, característicos das práticas construcionistas sociais em terapia. 


\section{A terapia focada na solução e as práticas construcionistas}

Talvez o movimento de mudança mais enfático trazido pelo construcionismo social para as práticas terapêuticas seja o privilégio atribuído ao discurso, em substituição ao tradicional foco na mente individual. A passagem ocorre com a compreensão de que é nos processos discursivos que os significados podem surgir. Considerando que os significados construídos pelas pessoas por meio da linguagem funcionam como organizadores de suas vidas, incluindo o que falam sobre si mesmas e sobre o mundo, o interesse da terapia construcionista se volta para práticas que privilegiem a produção de significado no discurso e suas implicações para as vidas dos clientes. O terapeuta considera as diferentes formas de descrição de si, nos diversos contextos situados, e, ainda, volta sua atenção para as variadas maneiras de dar sentido às experiências diárias.

Sob esse aspecto, pode-se considerar que a Terapia Focada na Solução se aproxima do construcionismo social na medida em que entende que as descrições produzidas na conversa terapêutica podem construir determinadas versões de realidade sobre as vidas dos clientes. Isso fica muito claro em duas das principais técnicas utilizadas: a pergunta do milagre e as perguntas de escala. Elas servem como convites a conversas que ajudem os clientes a"reconstruir e remodelar suas realidades, de maneira que eles vejam como útil" (Berg \& de Shazer, 1993, p.9) e criem o espaço para a negociação de sentidos em discurso sobre quais devam ser as metas e como a terapia está prosseguindo, entre outras possibilidades.

Existe um tensionamento importante em relação a essa proposta construcionista, pois as intervenções estão pautadas em mudanças comportamentais, pouco focalizadas na importância da mudança dos discursos. A pergunta do milagre permite a construção de discursos nos quais a queixa não ocorre, mas tais discursos são enfatizados pelo terapeuta apenas como pistas sobre qual caminho ele deve seguir na definição das tarefas de casa e do processo terapêutico como um todo. Em contraposição a isso, todavia, de Shazer (1985) afirma que relatos de mudança são indicadores de sucesso terapêutico bons o suficiente.
A segunda mudança para as práticas construcionistas está intimamente ligada à discussão anterior e é caracterizada por uma passagem da ênfase no selfe nos significados construídos pessoalmente por mentes individuais, para uma primazia no entendimento das relações como o local de produção de sentidos. Essa mudança entende que o conhecimento sobre si mesmo e sobre o mundo só pode ser gerado nas diversas relações em que uma pessoa se insere, dentre as quais a relação terapêutica também pode estar (Gergen \& Warhuus, 2001).

Assim, uma breve discussão epistemológica pode ser útil para a compreensão de como a Terapia Focada na Solução pode ser pensada com relação a essa ênfase de Shazer (1991) coloca a Terapia Focada na Solução como fortemente influenciada pela proposta construtivista social. De acordo com Gergen (1997) e Grandesso (2000), o construtivismo se aproxima de uma concepção construcionista social no que tange ao foco na construção do conhecimento, sem concebê-la como a apreensão de uma realidade objetiva. Além disso, as duas perspectivas partilham também o entendimento de que a mente humana não é um reflexo da realidade objetiva por meio da observação desta. As duas propostas se diferenciam, entretanto, entre outros aspectos, quando teorizam sobre a constituição de self. Enquanto o construcionismo social o considera como uma realização discursiva construída de forma dialógica, nas relações situadas (Gergen, 1991), o construtivismo se caracteriza por um foco mentalista ao procurar processos intrínsecos aos indivíduos. Nesse sentido, de Shazer fala de realidades construídas, mas concebe a existência de visões de mundo que surgem por meio da percepção da realidade, que é individual e interfere nas diferentes relações estabelecidas. As relações, dessa forma, são colocadas como uma decorrência ou produto de interações entre indivíduos isolados, o que se diferencia de uma perspectiva construcionista.

Decorrente tanto da ênfase no discurso quanto da ênfase relacional, o terceiro movimento construcionista, do qual Gergen e Warhuus (2001) falam, trata de um distanciamento da noção de singularidade em direção à ideia de polivocalidade, que pode ser resumida como a ênfase em múltiplas realidades possíveis para o cliente. Isso vale para o abandono tanto da concepção da existência de uma única verdade quanto da ideia de 
um self unificado e coerente diante de toda situação e independente do contexto relacional no qual está inserido.

A respeito do abandono da busca por uma verdade, a Terapia Focada na Solução partilha da mesma ideia na medida em que a procura por uma precisão avaliativa e descritiva do que realmente está se passando com o cliente não é de sua preocupação, abrindo caminho para a construção de futuros alternativos ou preferidos. Ela não se preocupa, ainda, com a formulação de uma teoria sobre o problema ou a patologia. Considera que existem inúmeras formas de se descrever o problema e que diferentes formas de apresentar uma queixa influenciam sobre o que conta como a realidade do cliente. Sobre o abandono da ideia de um self unificado, como já discutido a respeito da ideia de self que sustenta a proposta focada na solução, ela se pauta na existência de indivíduos coerentes e com self unificado, o que a distancia das práticas terapêuticas orientadas pela sensibilidade construcionista social.

Outra mudança identificada ao discurso construcionista sugere um deslocamento dos problemas para as potencialidades, no qual essas são possibilidades de construção de discursos alternativos àqueles nos quais o problema é central. O problema é considerado como uma forma possível de descrição, submetida às significações construídas nas relações por meio de convenções linguísticas. A prática da Terapia Focada na Solução partilha dessa ênfase de forma significativa: o terapeuta volta-se para a procura de exceções, ou seja, de situações da vida do cliente que são descritas como solução. No intuito de possibilitar um espaço para que tais discursos se produzam as perguntas do milagre são uma técnica bastante interessante. Tais características podem ser entendidas como um disparador para a construção de discursos alternativos sobre as vivências do cliente, considerando suas potencialidades, suas possibilidades de mudança e, ainda, focando nas experiências futuras.

O último movimento associado às práticas terapêuticas construcionistas sociais pode ser descrito como uma passagem do tradicional insight individual para a ação. Para o construcionismo, a suposição de que a mudança terapêutica ocorrida dentro do consultório será levada para todos os outros contextos da

118 vida do cliente é duvidosa. Por essa perspectiva, o signi- ficado está em constante negociação e pode mudar em cada conjunto de relações. Dessa forma,

"as questões principais a colocar sobre a coconstrução terapêutica são: (1) se uma forma particular de discurso é acionável fora da relação terapêutica e (2) se as consequências pragmáticas desse discurso são desejáveis" (Gergen \& Warhuus, 2001, p. 53).

Nesse sentido, destaca-se na Terapia Focada na Solução a presença de uma especificação da ênfase construcionista na ação. Ela se preocupa com o que de Shazer (1988) chamou de transferência, conceito utilizado para a ideia de aplicação da mudança situada na relação terapêutica para as relações de outros contextos diversos. Isso é feito, sobretudo, por meio da prescrição de tarefas definidas pelo terapeuta para execução por parte do cliente, acreditando que elas podem conter elementos da mudança construída no contexto terapêutico. Os terapeutas focados na solução acreditam que a execução das tarefas prescritas possibilite a ocorrência de tais mudanças em contextos relacionais mais amplos. Vale ressalvar, entretanto, que essa é uma conceituação enraizada nas propostas sistêmicas e aparece no contexto da Terapia Focada na Solução com um traço comportamental e individualizado, distinto da ênfase construcionista específica.

Além disso, essa análise comparativa da Terapia Focada na Solução permitiu observar como ela compartilha com outras propostas terapêuticas construcionistas (reflexivas, colaborativas e narrativas) alguns desafios apontados por Rasera e Japur (2004) referentes aos vocabulários sobre o self e à concepção de social. Assim, as concepções de self implicadas pela Terapia Focada na Solução sustentam, ainda que de forma mais intensa que as outras propostas construcionistas, certa marca individualista e, até mesmo, mentalista. Da mesma forma, em relação à concepção de social, percebe-se na Terapia Focada na Solução um privilégio do contexto microssocial de produção de sentido, sem um compromisso com a articulação da prática terapêutica ao contexto social mais amplo.

Finalizando, a análise realizada também traz questões sobre os próprios critérios utilizados, entendendo que os contornos do que seja uma terapia construcionista são também construções retóricas e não definidas a priori (Rasera \& Japur, 2004). Assim, é importante não naturalizar as práticas terapêuticas tanto como 
sendo construcionistas em si mesmas quanto como se apresentando como propostas superiores a outras. Uma maneira de evitar esses riscos pode ser pensar na Terapia Focada na Solução como uma opção discursiva para a terapia (McNamee, 2004a, 2004b). Assim compreendida, o exercício reflexivo se volta para a compreensão do vocabulário produzido pela Terapia Focada na Solução como útil em alguns contextos terapêuticos, podendo levar a conversas que produzam discursos mais generativos para as vidas dos clientes, mas, como todo discurso, nem sempre contribuindo para o andamento do processo terapêutico.

\section{Considerações Finais}

A análise proposta neste artigo permite considerar em que medida a Terapia Focada na Solução se aproxima do discurso construcionista social e em quais pontos ocorrem tensões entre suas proposições teóricas. Percebe-se como a ênfase nas potencialidades e na ação, bem como o abandono pela busca por uma descrição mais verdadeira sobre a realidade do cliente, colocam o citado modelo terapêutico próximo às posturas e práticas construcionistas, privilegiando uma compreensão da linguagem como construtora da realidade para os clientes. Já o terapeuta focado na solução apresenta ainda uma postura diretiva e de especialidade hierárquica no processo terapêutico, o que se diferencia da postura associada ao construcionismo social. Além disso, o modelo está focado em mudanças comportamentais e não se estrutura a partir de uma reflexão sobre os valores presentes em seu fazer terapêutico. Suas concepções de self, associadas à noção de "visões de mundo", são também um ponto de tensão teórica, e demonstram as influências de outros suportes teóricos na construção do modelo de terapia em questão.

A análise sobre as aproximações e os distanciamentos deve sustentar uma reflexão sobre as implicações do uso das contribuições da Terapia Focada na Solução para cada contexto terapêutico situado, tornando-a um recurso útil ao terapeuta e evitando seu uso de forma a restringir a conversação e a impor um caminho terapêutico pré-determinado. É esse exercício de pensamento, análise e crítica das diversas propostas construcionistas no campo da terapia que pode promover sua difusão de forma abrangente, criativa e transformadora.

\section{Referências}

Andersen, T. (1999). Processos reflexivos. Rio de Janeiro: Instituto Noos.

Anderson, H. (1997). Conversation, language and possibilities. New York: Basic Books.

Anderson, H., \& Goolishian, H. (1998). O cliente é o especialista. In S. McNamee \& K. J. Gergen (Orgs.), A terapia como construção social (pp.201-202). Porto Alegre: Artes Médicas.

Bateson, G. (1972). Steps to an ecology of mind. San Francisco: Chandler.

Berg, I., \& de Shazer, S. (1993). Making numbers talk: Language in therapy. In S. Friedman (Ed.), The new language of change: Constructive collaboration in psychotherapy (pp.5-24). New York: The Guilford Press.

Bidwell, D. R. (2007). Miraculous knowing: Epistemology and solution-focused therapy. In T. S. Nelson \& F. N. Thomas (Eds.), Handbook of solution-focused therapy: Clinical applications (pp.65-87). New York: The Haworth Press.

Carrijo, R. S., \& Rasera, E. F. (2010). Mudança em psicoterapia de grupo: reflexões a partir da terapia narrativa. Psicologia Clínica, 22(1), 125-140.

DeJong, P., \& Berg, I. K. (2008). Interviewing for solutions. Pacific Grove, CA: Brooks.

de Shazer, S. (1985). Keys to solution in brief therapy. New York: WW Norton \& Company.

de Shazer, S. (1988). Clues: Investigating solutions in brief therapy. New York: WW Norton \& Company.

de Shazer, S. (1991). Putting difference to work. New York: WW Norton \& Company.

de Shazer, S. (1994). Words were originally magic. New York: WW Norton \& Company.

Erickson, M., Rossi, E., \& Rossi, S. (1976). Hypnotic realities: The induction of clinical hypnosis and forms of indirectsuggestion. New York: Irvington.

Gergen, K. J. (1991). The saturated self: Dilemmas of identity in contemporary life. New York: Basic Books.

Gergen, K. J. (1997). Realities and relationships. Cambridge: Harvard University Press.

Gergen, K. J. (1999). An invitation to social construction. London: Sage.

Gergen, K. J. (2006). Construir la realidad. Buenos Aires: Paidós.

Gergen, K. J., \& Gergen, M. (2010). Construcionismo social:um convite ao diálogo. Rio de Janeiro: Instituto Noos.

Gergen, K. J., \& Warhuss, L. (2001). Terapia como construção social: características, reflexões, evoluções. In M. M. Gonçalves \& O. F. Gonçalves (Orgs.), Psicoterapia, discurso e narrativa: a construção conversacional da mudança (pp.29-64). Coimbra: Quarteto Editora.

Grandesso, M. (2000). Sobre a reconstrução do significado. São Paulo: Casa do Psicólogo. 
Guanaes, C. (2006). A construção da mudança em terapia de grupo. São Paulo: Vetor.

Holzman, L., \& Mendes, R. (2003). Psychological investigations. New York: Brunner-Routledge.

McNamee, S. (2004a). Social construction as practical theory. In D. Pare \& G. Larner (Eds.), Collaborative practice in psychology and therapy (pp.9-22). New York: Haworth Press.

McNamee, S. (2004b). Therapy as social construction: Back to basics and forward toward challenging issues. In T. Strong \& D. Pare (Orgs.), Furthering talk: Advances in the discursive therapies (pp.253-270). New York: Kluwer Academic.

McNamee, S., \& Gergen, K. J. (Orgs.). (1998). A terapia como construção social. Porto Alegre: Artes Médicas.
Rasera, E. F., \& Japur, M. (2004). Desafios da aproximação do construcionismo social ao campo da psicoterapia. Estudos de Psicologia (Natal), 9(3), 431-439.

Rasera, E. F., \& Japur, M. (2007). Grupo como construção social. São Paulo: Vetor.

Sharry, J. (2001). Solution-focused groupwork. London: Sage Publications.

White, M., \& Epston, D. (1990). Medios narrativos para fines terapéuticos. Buenos Aires: Paidós.

Wittgenstein, L. (1975). Philosophical remarks. Chicago: University of Chicago Press.

Recebido em: 12/9/2011

Versão final em: 18/11/2011

Aprovado em: 29/11/2011

120 